

\title{
Bioconversie van digestaat door wormen: productie van eiwit en compost
}

Hellen Elissen \& Rommie van der Weide 


\section{Bioconversie van digestaat door wormen: productie van eiwit en compost}

Hellen Elissen ${ }^{1} \&$ Rommie van der Weide ${ }^{1}$

1 Wageningen University \& Research

Dit onderzoek is in opdracht van de PPS Biobased opwaarderen mest en digestaat AF-17052b uitgevoerd door de Stichting Wageningen Research (WR), business unit Open Teelten. Dit project ontvangt financiële steun van de Topsector Agri \& Food. Binnen de Topsector werken bedrijfsleven, kennisinstellingen en de overheid samen aan innovaties voor veilig en gezond voedsel voor 9 miljard mensen in een veerkrachtige wereld.

WR is een onderdeel van Wageningen University \& Research, samenwerkingsverband tussen Wageningen University en de Stichting Wageningen Research.

Wageningen, December 2019

Rapport WPR-815 
Elissen, H. \& R. van der Weide, 2019. Bioconversie van digestaat door wormen: productie van eiwit en compost. Wageningen Research, Rapport WPR-815. 24 blz.; 5 fig.; 3 tab.; 9 ref.

Dit rapport is gratis te downloaden op https://doi.org/10.18174/515044

Samenvatting: Dit rapport beschrijft groei op en omzetting van de dikke fractie ( $28 \%$ droge stof) van digestaat door $E$. fetida wormen (compostwormen) in 6 kweekbedden van elk $5 \mathrm{~m}^{2}$. De begindichtheid van de wormen was $5 \mathrm{~kg} / \mathrm{m}^{2}$. Het digestaat was afkomstig uit de ACRRES vergister die gevoed werd met rundermest en natuurgras. In de vijf weken durende proef bij Lumbriculus te Oostwold werd het voorgecomposteerde digestaat continu omgezet in wormencompost waarbij $22 \%$ (natgewicht) van het digestaat afgebroken werd. De omzettingssnelheid was 1.6-3.2 kg (3.2-6.4 L) per kg levende wormen $\left(\right.$ per $\left.\mathrm{m}^{2}\right)$ per week. Door het opeten van het digestaat veranderden structuur van en nutriënten in het digestaat: De ontstane wormencompost had een korrelige lichte structuur en ammoniak nam bijvoorbeeld met $65 \%$ af. Ook groeiden de wormen in biomassa en produceerden ze cocons. De gemiddelde groei in natte wormenbiomassa was $4 \%$ per week. De maximale snelheden werden nog niet bereikt in dit experiment, maar het is duidelijk dat vermicompostering tot een substantiële afbraak van de dikke fractie van digestaat leidt en de productie van een nieuwe meststof (wormencompost) en nieuw eiwit (wormenbiomassa).

Trefwoorden: wormencompost, vermicompost, Eisenia fetida, compostwormen, bioconversie, digestaat, dikke fractie, eiwit

(c) 2019 Wageningen, Stichting Wageningen Research, Wageningen Plant Research, Business unit Open Teelten, Postbus 430, 8200 AK Lelystad; T 0320 - 291 111; www.wur.nl/plant-research

KvK: 09098104 te Arnhem

VAT NL no. 8113.83.696.B07

Stichting Wageningen Research. Alle rechten voorbehouden. Niets uit deze uitgave mag worden verveelvoudigd, opgeslagen in een geautomatiseerd gegevensbestand, of openbaar gemaakt, in enige vorm of op enige wijze, hetzij elektronisch, mechanisch, door fotokopieën, opnamen of enige andere manier zonder voorafgaande schriftelijke toestemming van Stichting Wageningen Research.

Stichting Wageningen Research is niet aansprakelijk voor eventuele schadelijke gevolgen die kunnen ontstaan bij gebruik van gegevens uit deze uitgave.

\section{Rapport WPR-815}

Foto omslag: Jean Mekelenkamp 


\section{Inhoud}

$\begin{array}{ll}\text { Woord vooraf } & 5\end{array}$

$\begin{array}{ll}\text { Samenvatting } & 7\end{array}$

$\begin{array}{lr}\text { Inleiding } & 9\end{array}$

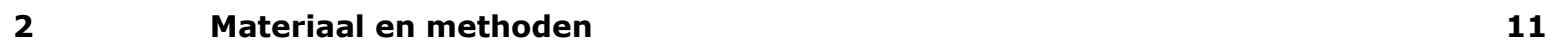

$\begin{array}{llr}3 & \text { Resultaten } & 13\end{array}$

$\begin{array}{llr}4 & \text { Conclusie } & 15\end{array}$

$\begin{array}{ll}\text { Literatuur } & 17\end{array}$

Bijlage 1 Compostanalyse dikke fractie digestaat 19

Bijlage 2 Bemestende waarde analyse dikke fractie digestaat 21

$\begin{array}{lll}\text { Bijlage } 3 & \text { Compostanalyse vermicompost van digestaat } & 23\end{array}$

Bijlage 4 Bemestende waarde analyse vermicompost van digestaat $\quad 25$ 



\section{Woord vooraf}

In Nederland zijn er overschotten aan mest en digestaten (vergiste mest en reststromen) waardoor deze een negatieve waarde vertegenwoordigen. Tegelijkertijd bevatten deze reststromen waardevolle ingrediënten voor de productie van biomassa (als grondstof voor food- en feed producten), voor verbetering van bodemkwaliteit en voor energieproductie. Het aantal haalbare businesscases waarbij de reststroom opgewaardeerd wordt is tot dusver beperkt. Dit heeft zowel te maken met het rendement van de gehanteerde technologieën als de wet- en regelgeving gerelateerd aan de reststromen.

Recente informatie uit onderzoek, wetenschappelijke literatuur en van de bedrijven geeft nieuwe aanknopingspunten voor een biobased opwaardering van mest/digestaat stromen en het verbeteren van het rendement van vergisting. Het vernieuwende aan ons onderzoek is het telen van alternatieve biomassa op de reststromen en het gebruik van omzettingsproducten voor het verbeteren van de vergisting. Het gaat hier om het gebruik van gescheiden mest en digestaat producten voor de teelt van paddenstoelen/schimmels, wormen, insecten, specifieke bacteriën en aquatische biomassa. De ontstane biomassa kan verder geraffineerd en vermarkt worden als food, feed en biobased grondstof. Ook resteren er bewerkte mest en digestaat producten die bovendien waarde hebben als bemestingsproducten voor bodem en plantengroei, als substraat voor verbetering van vergisting of voor export/gebruik buiten de landbouw. Dit geeft een nieuwe invulling aan de verplichte mestverwerking.

Doel van dit project is om deze ideeën verder te exploreren en te onderbouwen/testen op lab- en praktijkschaal, leidend tot een proof of principle voor nieuwe biobased opwaarderingsmethoden van mest en digestaat die in samenhang ingezet kunnen worden om kringlopen beter te sluiten en/of buiten de reguliere landbouw af te zetten. Hierbij worden knelpunten in wet- en regelgeving verkend en geagendeerd. Tevens worden kengetallen berekend die nodig zijn voor beoordeling van de duurzaamheid (o.a. kosten, milieueffecten) en voor dossiervorming over regelgeving (o.a. mineralen, voedselveiligheid).

De veehouderijsector krijgt inzicht in de mogelijkheden van biobased verwaarden en beter afzetten van hun belangrijkste reststromen. Voor de betrokken MKB bedrijven levert dit onderzoek o.a. proof of principle voor hun technologie en input in hun business cases. De gecombineerde effecten van de technologieën levert nieuwe kennis, methodes en onderzoeksrichtingen voor de wetenschap. In maatschappelijke context draagt het ook op andere manieren gebruiken en opwaarderen van mest en digestaten bij aan de transitie naar een circulaire bio-economie met een efficiënte en duurzame agrifoodsector.

Meer informatie:

- http://www.acrres.nl/projecten_acrres/biobased-opwaarderen-mest-en-digestaat/

- Rommie van der Weide: rommie.vanderweide@wur.nl, +31320291631

- Hellen Elissen: hellen.elissen@wur.nl, +31320291223

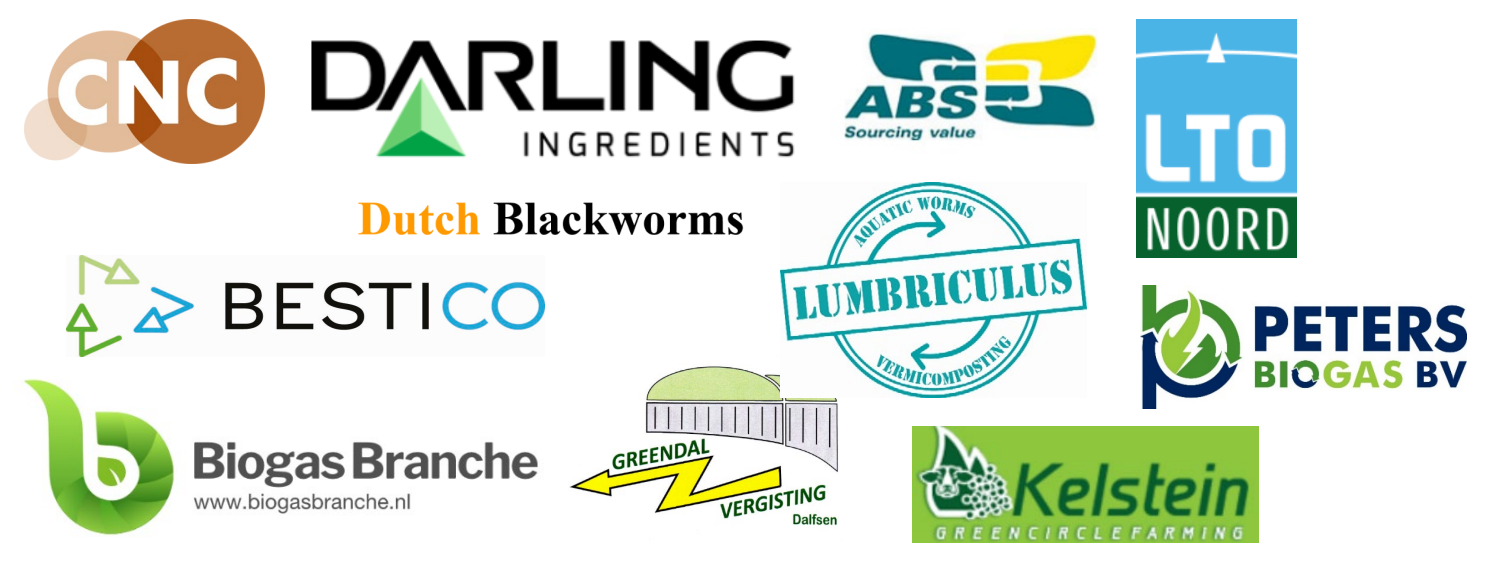




\section{Samenvatting}

Dit rapport beschrijft groei op en omzetting van de dikke fractie (28\% droge stof) van digestaat door E. fetida wormen (compostwormen) in 6 kweekbedden van elk $5 \mathrm{~m}^{2}$. De begindichtheid van de wormen was $5 \mathrm{~kg} / \mathrm{m}^{2}$. Het digestaat was afkomstig uit de ACRRES vergister die gevoed werd met rundermest en natuurgras. In de vijf weken durende proef bij Lumbriculus te Oostwold werd het voorgecomposteerde digestaat continu omgezet in wormencompost waarbij $22 \%$ (natgewicht) van het digestaat afgebroken werd. De omzettingssnelheid was 1.6-3.2 kg (3.2-6.4 L) per kg levende wormen (per $\mathrm{m}^{2}$ ) per week. Door het opeten van het digestaat veranderden structuur van en nutriënten in het digestaat: De ontstane wormencompost had een korrelige lichte structuur en ammoniak nam bijvoorbeeld met $65 \%$ af t.o.v. het uitgangsmateriaal. Ook groeiden de wormen in biomassa en produceerden ze cocons. De gemiddelde groei in natte wormenbiomassa was $4 \%$ per week. De maximale snelheden werden nog niet bereikt in dit experiment, maar het is duidelijk dat vermicompostering tot een substantiële afbraak van de dikke fractie van digestaat leidt en de productie van een nieuwe meststof (wormencompost) en nieuw eiwit (wormenbiomassa). 


\section{$1 \quad$ Inleiding}

Van compostwormen (Eisenia fetida) is bekend dat zij een groot scala aan organische materialen kunnen omzetten (vermicomposting). De volgende wetenschappelijke publicaties specifiek over digestaat tonen aan dat E. fetida wormen geschikt zijn voor het vermicomposteren van digestaat: Hanc and Vasac, 2015; Krishnasamy et al, 2014; Nguyen, 2012; Sangwan et al, 2008; Suthar, 2009; Suthar, 2010; Vijaya, 2010; Yadav and Garg, 2014; Yadav et al, 2013 (Tabel 1).

Tabel 1 Overzicht van resultaten uit artikels over vermicomposteren van digestaat door E. fetida.

\begin{tabular}{|c|c|c|}
\hline Substraat & Belangrijkste resultaten & Referentie \\
\hline $\begin{array}{l}\text { Dikke fractie digestaat, voedselafval } \\
\text { en groente vergister }\end{array}$ & Afname pathogenen en toename waardevolle nutriënten & $\begin{array}{l}\text { Krishnasamy et al, } \\
2014\end{array}$ \\
\hline $\begin{array}{l}\text { Dikke fractie digestaat drijfmest en } \\
\text { maisvergister }\end{array}$ & $\begin{array}{l}\text { Afname digestaat, toename wormengroei en toename } \\
\text { waardevolle nutriënten. Afname van pathogenen. }\end{array}$ & Nguyen, 2012 \\
\hline $\begin{array}{l}\text { Vers digestaat van een } \\
\text { boerderijvergister (veeteelt) }\end{array}$ & $\begin{array}{l}\text { Afname digestaat, toename wormengroei en toename } \\
\text { waardevolle nutriënten }\end{array}$ & $\begin{array}{l}\text { Sangwan et al, } \\
2008\end{array}$ \\
\hline $\begin{array}{l}\text { Gedroogd vers digestaat van koemest } \\
\text { vergister }\end{array}$ & $\begin{array}{l}\text { Afname digestaat, toename wormengroei en toename } \\
\text { waardevolle nutriënten }\end{array}$ & Suthar, 2010 \\
\hline Vers digestaat van koemest vergister & $\begin{array}{l}\text { Omzetting van digestaat in vermicompost met verbeterde } \\
\text { eigenschappen }\end{array}$ & $\begin{array}{l}\text { Yadav and Garg, } \\
2014\end{array}$ \\
\hline Vers digestaat van koemest vergister & $\begin{array}{l}\text { Omzetting van het digestaat in geurloos, homogeen, } \\
\text { gestabiliseerd humusachtig product }\end{array}$ & Yadav et al, 2013 \\
\hline
\end{tabular}

Digestaat wordt dus opgenomen door de wormen, gedeeltelijk verteerd en uiteindelijk omgezet in waardevolle vermicompost (wormencompost) en nieuwe wormenbiomassa. Om de haalbaarheid van deze technologie lokaal aan te tonen is door Lumbriculus en WUR ACRRES gekeken naar de omzetting van de dikke fractie van digestaat van de ACRRES co-vergister (rundermest/gras/co-producten) te Lelystad. Het doel was vast te stellen wat de compostwormen doen met de structuur/samenstelling/hoeveelheid van het digestaat en of de wormen kunnen groeien op de organische stof aanwezig in het digestaat. Hiervoor werden een aantal proeven in kweekbedden ingezet op locatie bij Lumbriculus te Oostwold (Nederland) zoveel mogelijk onder omstandigheden die schaalbaar zijn en/of gangbaar in huidige grootschalige

vermicomposteerinstallaties/wormenkweekbedrijven (o. a. realistische laagdikte, wormendichtheden en doorvoersnelheden).

Voor een aantal parameters is het belangrijk dat het digestaat 'voorgecomposteerd' wordt: door dit (spontane) thermofiele proces ondergaat het materiaal een hittestap en wordt toxiciteit voor de wormen (hitte, ammonia, anaerobe gassen, te hoge/lage pH) voorkomen (Nguyen, 2012). Ook kunnen op deze manier pathogenen vernietigd worden. Verschillende onderzoeken passen dit toe zoals beschreven in Tabel 2.

Tabel 2 Methodes voorcomposteren uit literatuur.

\begin{tabular}{ll} 
Methode & Referentie \\
2 weken mbv speciaal belucht composteringsvat & Hanc and Vasac, 2015 \\
\hline 15 dagen door dagelijks keren van de mengsels, ook vochtig houden & Krishnasamy et al, 2014 \\
\hline 1 week laten liggen, drogen bij kamertemperatuur en aanzuren met HCl & Nguyen, 2012 \\
\hline 15 dagen door regelmatig keren & Sangwan et al, 2008 \\
\hline 3 weken in bakken, om de drie dagen keren, nat houden 65\% & Suthar, 2009 \\
\hline 3 weken in bakken, om de drie dagen keren, nat houden 65\% & Suthar, 2010 \\
\hline 3 weken door dagelijks keren & Yadav and Garg, 2014 \\
\hline 3 weken in ronde containers bewaren & Yadav et al, 2013 \\
\hline
\end{tabular}




\section{Materiaal en methoden}

Deze proef is in zesvoud uitgevoerd in kweekbedden van $5 \mathrm{~m}^{2}$ (Figuur 1).

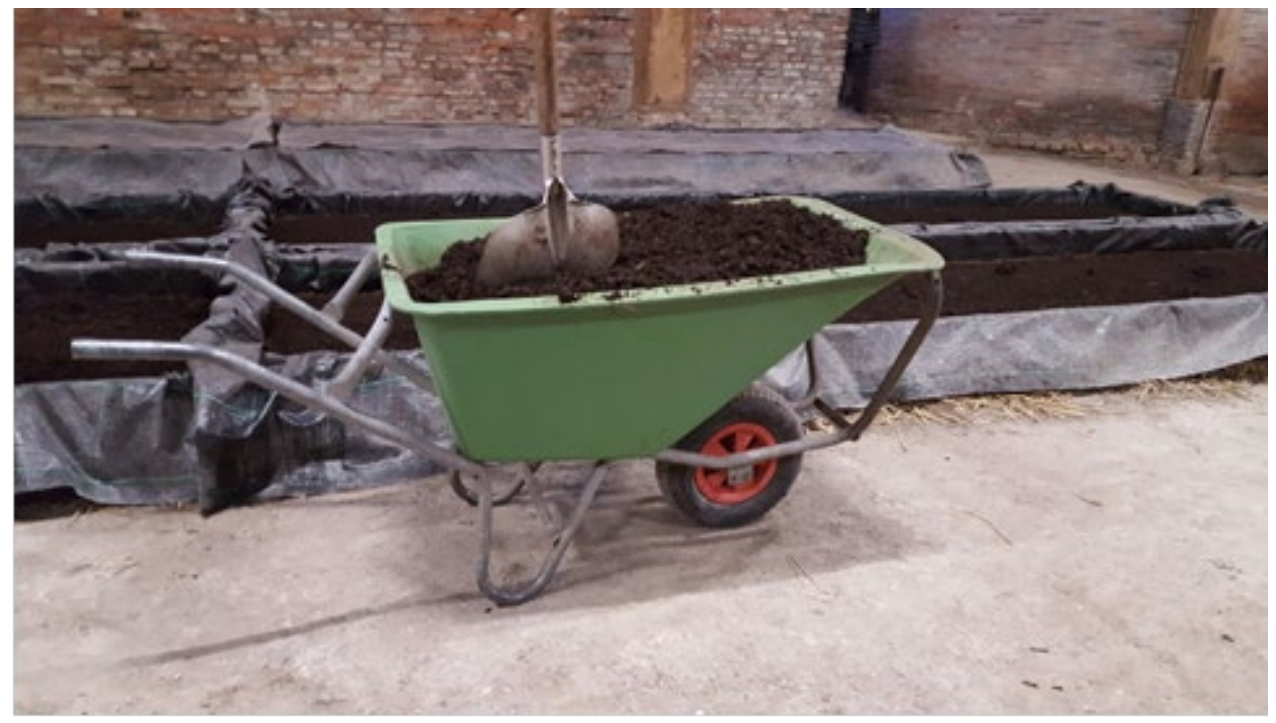

Figuur 1 Foto van de gebruikte bedden met op de voorgrond kruiwagen met dikke fractie digestaat.

De bedden zijn gemaakt van een houten geraamte met daarin stevig antiworteldoek. Onder de bak en doek is een 20 centimeter dikke laag van aangedrukt stro aangebracht om de temperatuur in de bakken constant te houden. Als substraat is de dikke fractie van ACRRES digestaat gebruikt (van een co-vergister in Lelystad op rundermest/gras/co-producten). Het digestaat werd na ophalen uit Lelystad afgedekt bewaard in een laag van ca. 30 centimeter en wekelijks gekeerd. In elk bed zijn bij de start $25 \mathrm{~kg}$ levende wormen gebracht (Figuur 2).
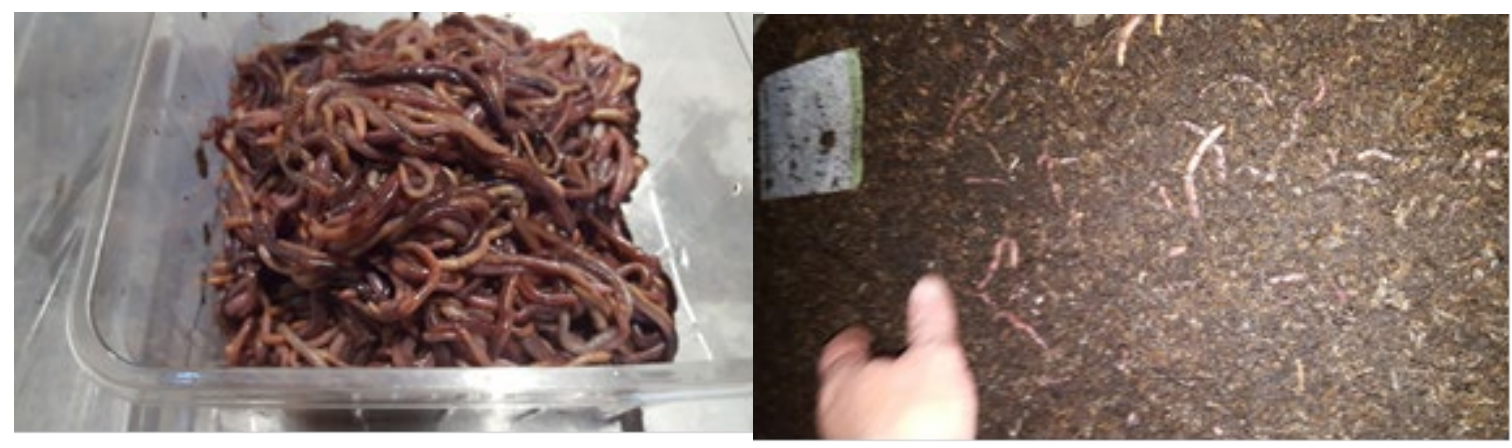

Figuur 2 Afgewogen E. fetida wormen (links) en wormen nadat ze zich verspreid hebben in het digestaat (rechts).

De bedden werden afgedekt met een zeil. De proef liep gedurende 5 weken. De eerste drie weken werd per bed $80 \mathrm{~L}$ (dichtheid $500 \mathrm{~kg} / \mathrm{m}^{3}$ ) digestaat opgebracht (laagdikte $16 \mathrm{~cm}$ ) maar in de voorlaatste week (week 4) de dubbele hoeveelheid (160 L). In week 5 werd geen nieuw digestaat opgebracht. 


\section{Resultaten}

De wormen gedijden gedurende de hele proef goed op het digestaat, bleven uniform verdeeld in het bed zitten (als de omstandigheden ongunstig zijn verlaten ze het bed) en groeiden in vijf weken met 1 $\mathrm{kg}$ levende wormen per $\mathrm{m}^{2}$. Dit betekent een gemiddelde groei van $4 \%$ per week in wormenbiomassa, en ongeveer een verdubbeling van de totale biomassa elk half jaar. Gedurende de proeven werden er cocons en parende wormen aangetroffen in het digestaat wat wijst op een zich voortplantende en groeiende wormenpopulatie (Figuur 3).

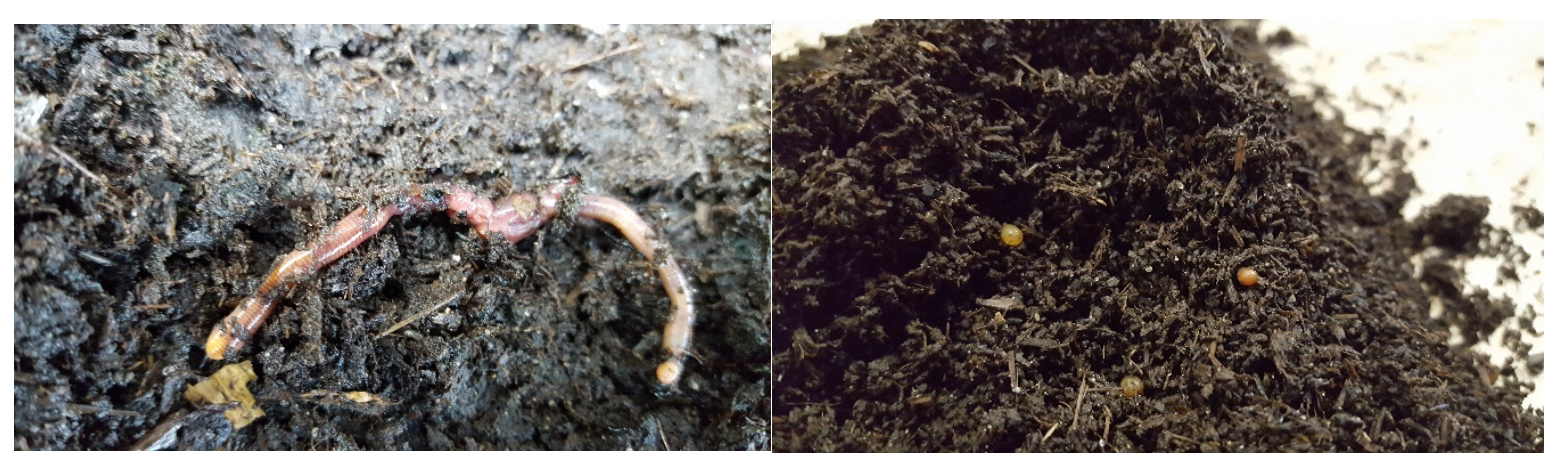

Figuur 3 Parende E. fetida wormen (links) en cocons (rechts) in de bedden met digestaat.

De wormen maken de structuur van het digestaat fijner (Figuren 4 en 5).
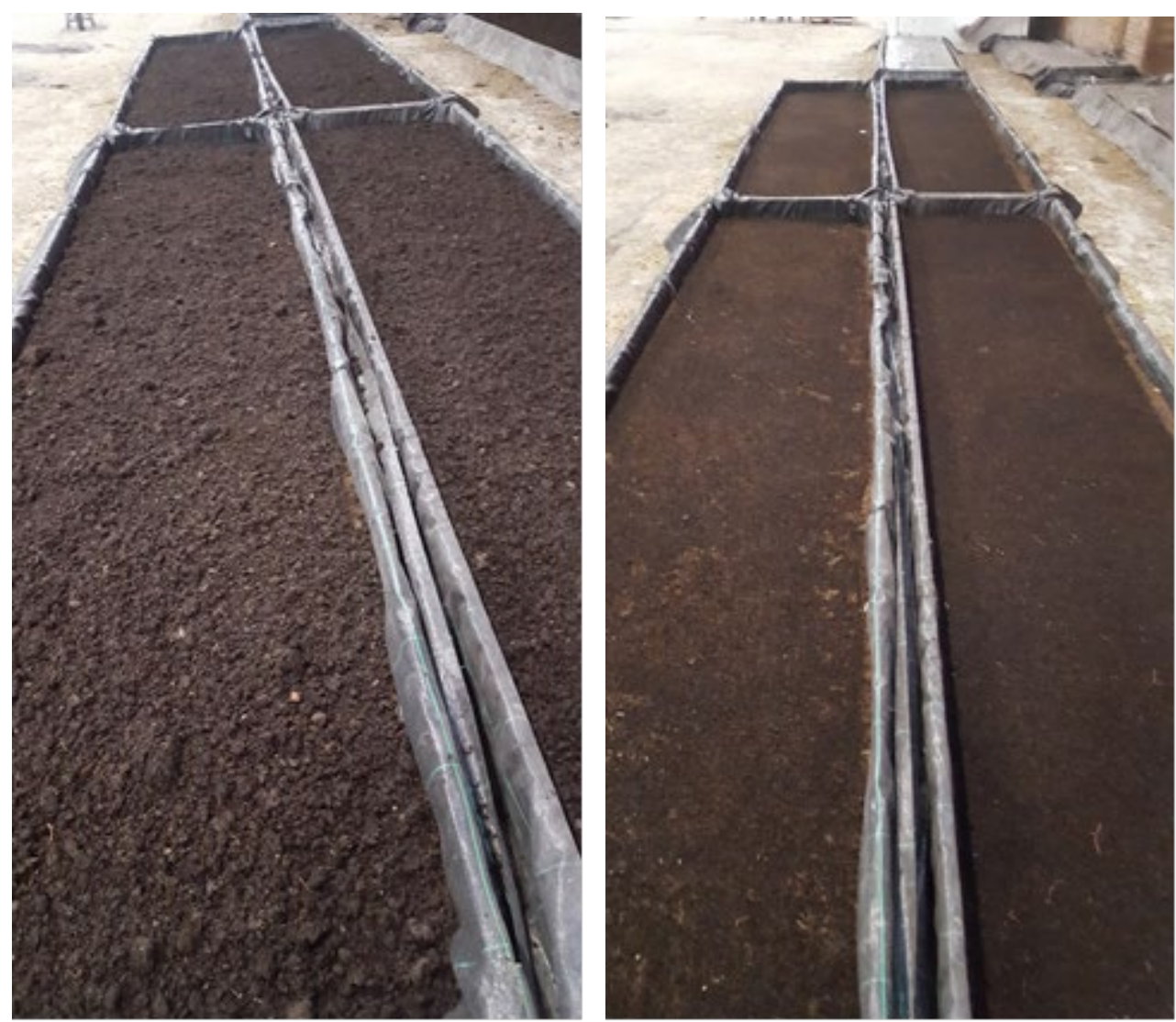

Figuur $4 \quad K w e e k b e d d e n$ met dikke fractie digestaat voor (links) en na (rechts) vermicomposteren. 


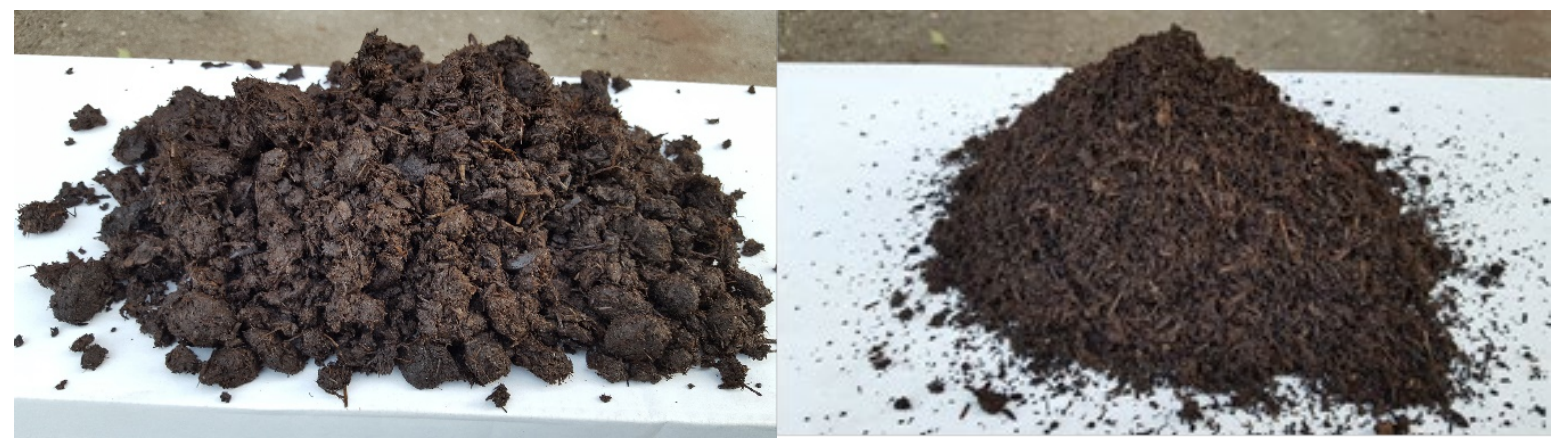

Figuur 5 Close-up dikke fractie digestaat voor (links) en na (rechts) vermicomposteren.

Zowel van begin- als eindmateriaal (digestaat resp. vermicompost) werden representatieve monsters genomen die geanalyseerd zijn door Eurofins Agro (Wageningen, Nederland). Tabel 3 laat de belangrijkste veranderingen zien en de gedetailleerde analyses staan in Bijlages 1 en 2 voor de samenstelling voor en Bijlages 3 en 4 voor de samenstelling na vermicomposteren.

Tabel 3 Samenstelling van digestat (Voor) en vermicompost ( $\mathrm{Na}=$ na 1 week) gedurende proef in bedden.

\begin{tabular}{lll} 
Parameter & Voor & $\mathrm{Na}$ \\
$\mathrm{pH}$ & 7.6 & 6.4 \\
\hline $\mathrm{C} / \mathrm{N}$ ratio & 19 & 14 \\
\hline $\mathrm{N}$ totaal & $15.4 \mathrm{~g} / \mathrm{kg}$ DS & $20.5 \mathrm{~g} / \mathrm{kg} \mathrm{DS}$ \\
\hline $\mathrm{N}-\mathrm{NH}_{3}$ & $3.9 \mathrm{~g} / \mathrm{kg} \mathrm{DS}$ & $1.6 \mathrm{~g} / \mathrm{kg} \mathrm{DS}$ \\
\hline $\mathrm{As}$ & $473 \mathrm{~g} / \mathrm{kg} \mathrm{DS}$ & $490 \mathrm{~g} / \mathrm{kg} \mathrm{DS}$ \\
\hline Organische stof & $527 \mathrm{~g} / \mathrm{kg} \mathrm{DS}$ & $510 \mathrm{~g} / \mathrm{kg} \mathrm{DS}$ \\
\hline Fosfaat $\left(\mathrm{P}_{2} \mathrm{O}_{5}\right)$ & $16.0 \mathrm{~g} / \mathrm{kg} \mathrm{DS}$ & $16.0 \mathrm{~g} / \mathrm{kg} \mathrm{DS}$ \\
\hline Droge stof & $281 \mathrm{~g} / \mathrm{kg}$ & $310 \mathrm{~g} / \mathrm{kg}$ \\
\hline
\end{tabular}

Duidelijk was dat $\mathrm{pH}, \mathrm{C} / \mathrm{N}$ ratio, ammoniakgehalte en organische stof afnamen terwijl $\mathrm{N}$ totaal, droge stof gehalte en asrest toenamen (allen op droge stof basis). Het fosfaatgehalte in de droge stof bleef gelijk. Dit wordt ook beschreven in diverse literatuurbronnen.

De temperatuur in de bedden was steeds tussen 17 en $19^{\circ} \mathrm{C}$ en de $\mathrm{pH}$ rond 7.5 aan het begin van elke week. De dichtheid van het digestaat nam gedurende elke week af van $500 \mathrm{~kg} / \mathrm{m}^{3}$ naar 415 $\mathrm{kg} / \mathrm{m}^{3}$. Het digestaat werd dus luchtiger. Echter nam het totaal toegevoegde volume digestaat ( $400 \mathrm{~L}$ per bed) af naar $376 \mathrm{~L}$ in 5 weken. Het volume nam dus af met $6 \%$ terwijl het totale gewicht per bed afnam van $200 \mathrm{~kg}$ digestaat naar $156 \mathrm{~kg}$ vermicompost, een afname van $22 \%$.

Op basis van de massabalans (verdwenen hoeveelheid digestaat en bijbehorend veranderd droge stofgehalte) trad er een stijging van $15 \%$ op in $\mathrm{N}$ totaal en dalingen van $65 \%$ in ammoniak, $11 \%$ in as, $17 \%$ in organische stof en $14 \%$ in fosfaat.

Het toevoegen van de dubbele hoeveelheid digestaat in week 4 ten opzichte van de voorgaande 3 weken gaf geen problemen, maar de verwerkingstijd nam ook proportioneel toe met de hoeveelheid toegevoegd digestaat, afgaande op de structuurverandering van het digestaat. 


\section{$4 \quad$ Conclusie}

E. fetida wormen eten de dikke fractie van ACRRES digestaat met een snelheid van 1.6-3.2 kg (3.2$6.4 \mathrm{~L}$ ) per $\mathrm{kg}$ levende wormen (per $\mathrm{m}^{2}$ ) per week. Er zijn uit de literatuur snelheden bekend van ruim $5 \mathrm{~kg}$ (voerproduct) per kg levende wormen per week (Ndegwa and Thompson, 2000). De omzetting van de verdubbelde hoeveelheid digestaat in week 4 gaf ook aan dat de maximale omzettingssnelheid nog niet bereikt is. Door het opeten van het digestaat veranderen structuur van en nutriënten in het digestaat. Ook groeien de wormen in biomassa en produceren ze cocons. 


\section{Literatuur}

Hanc, A. and F. Vasak, 2015. Processing separated digestate by vermicomposting technology using earthworms of the genus Eisenia. International Journal of Environmental Science and Technology 12(4): 1183-1190

Krishnasamy, K., J. Nair and R. Bell, 2014. Evaluation of anaerobic digestate as a substrate for vermicomposting. International Journal of Environment and Waste Management 14(2): 149-164 Ndegwa, P. M. and S. A. Thompson, 2000. Effects of C-to-N ratio on vermicomposting of biosolids. Bioresource Technology 75(1): 7-12

Nguyen, P.-N. 2012. Vermicomposting of organic solid wastes as a biological treatment for sanitation. Ph.D. thesis Rheinischen Friedrich-Wilhelms-Universität, Bonn. 143 pp.

Sangwan, P., C. P. Kaushik and V. K. Garg, 2008. Vermiconversion of industrial sludge for recycling the nutrients. Bioresource technology 99 (18): 8699-8704

Suthar, S. 2009. Vermicomposting of vegetable-market solid waste using Eisenia fetida: Impact of bulking material on earthworm growth and decomposition rate. Ecological Engineering 35 (5): 914920

Suthar, S. 2010. Potential of domestic biogas digester slurry in vermitechnology. Bioresource Technology 101(14): 5419-5425

Yadav, A. and V. K. Garg, 2014. Effect of poultry waste on vermicomposting of anaerobically digested cattle dung slurry. International Journal of Environmental Technology and Management 17 (2/3/4): 154 - 164

Yadav, A., R. Gupta, and V. K. Garg, 2013. Organic manure production from cow dung and biogas plant slurry by vermicomposting under field conditions. International Journal Of Recycling of Organic Waste in Agriculture 2:21 


\section{Bijlage 1 Compostanalyse dikke fractie digestaat}

\section{eurofins}

Kwaliteitsonderzoek

Compost

Eurofins Agro

monster 3 a hellen

Uw klantnummer: 8278474

$\mathrm{NL}$ - $6700 \mathrm{AD}$ Wageningen

T monstername: Mathieu Eugelink: 0852002180

T klantenservice: $088876 \quad 1006$

E klantenservice.mest:@eurofins-agro.com

I www.eurofins-agro.com

\section{AcrTes WUR PPO}

D. Durksz

Edelhertwg 1

8219 PH LELYSTAD

\begin{tabular}{|c|c|c|c|c|c|}
\hline \multirow[t]{2}{*}{ Onderzoek } & $\begin{array}{l}\text { Analyse-/ordernummer: } \\
2018901608 / 004476421\end{array}$ & \multicolumn{2}{|c|}{$\begin{array}{l}\text { Datum verslag: } \\
15-10-2018\end{array}$} & \multicolumn{2}{|c|}{$\begin{array}{l}\text { Subsidieverlener: } \\
\text { Eurofins Agro, Kortingsregeling } \\
\text { Postbus } 170,6700 \text { AD WAGENINGEN }\end{array}$} \\
\hline & $\begin{array}{l}\text { Type monster: } \\
\text { Compost (overig) }\end{array}$ & \multicolumn{2}{|c|}{$\begin{array}{l}\text { Datum monstername: } \\
06-09-2018\end{array}$} & \multicolumn{2}{|l|}{$\begin{array}{l}\text { Datum ontvangst: } \\
11-09-2018\end{array}$} \\
\hline \multirow{27}{*}{$\begin{array}{l}\text { Resultaat } \\
\text { bepaald in het } \\
\text { monster volgens } \\
\text { deopgde. } \\
\text { hieronder } \\
\text { vermelde nomen }\end{array}$} & & Eenheid & Resultaat & Toetswaarde & Resultaat in produkt $(g / k g)$ \\
\hline & Droge stof & g/kg product & 291 & & \\
\hline & Ruw as & $\mathrm{g} / \mathrm{kg} \mathrm{ds}$ & 478 & & \\
\hline & Org. stof & $\%$ van de ds & 52,2 & 10.0 & \\
\hline & Stikstof (N) & $g / \mathrm{kg} d s$ & 15,4 & & 4.5 \\
\hline & Fosfor (P) & $g / k g d s$ & 7 & & \\
\hline & Fosfaat $\left(\mathrm{P}_{2} \mathrm{O}_{5}\right)$ & $\mathrm{g} / \mathrm{kg} \mathrm{ds}$ & 16.0 & & 4.66 \\
\hline & Kalium (K) & $g / k g d s$ & 16 & & \\
\hline & Kali $\left(\mathrm{K}_{2} \mathrm{O}\right)$ & $\mathrm{g} / \mathrm{kg} \mathrm{ds}$ & 18 & & 5.5 \\
\hline & Zwavel (S) & $\mathrm{g} / \mathrm{kg} \mathrm{ds}$ & 4.2 & & 1.2 \\
\hline & Magnesium (Mg) & $g / \mathrm{kg} d \mathrm{~s}$ & 6.2 & & \\
\hline & Magnesia $(\mathrm{MgO})$ & $g / \mathrm{kg} \mathrm{ds}$ & 10 & & 2.8 \\
\hline & Chloride & $\mathrm{g} / \mathrm{kg} \mathrm{ds}$ & 4.8 & & \\
\hline & Zuurgraad (pH) & & 7.6 & & \\
\hline & pH-water & & 7.7 & & \\
\hline & C-anorganisch & $\%$ & 0.18 & & \\
\hline & Koolzure kalk & $\%$ & 0.8 & & \\
\hline & Koolstof & $g / \mathrm{kg} \mathrm{ds}$ & 299,3 & & \\
\hline & $\mathrm{C} / \mathrm{N}$-ratio & & 19 & & \\
\hline & Cadmium (Cd) & $\mathrm{mg} / \mathrm{kg} \mathrm{ds}$ & 0.24 & 1,00 & \\
\hline & Chroom (Cr) & $\mathrm{mg} / \mathrm{kg}$ ds & 19 & 50 & \\
\hline & Koper (Cu) & $\mathrm{mg} / \mathrm{kg}$ ds & 25 & 90 & \\
\hline & Kwik ( $\mathrm{Hg})$ & $\mathrm{mg} / \mathrm{kg}$ ds & 0.04 & 0,30 & \\
\hline & Nikkel (Ni) & $\mathrm{mg} / \mathrm{kg} \mathrm{ds}$ & 11 & 20 & \\
\hline & Lood (Pb) & $\mathrm{mg} / \mathrm{kg}$ ds & $<6.4$ & 100 & \\
\hline & Zink (Zn) & $\mathrm{mg} / \mathrm{kg}$ ds & 101 & 290 & \\
\hline & Arseen (As) & $\mathrm{mg} / \mathrm{kg}$ ds & 1,2 & 15 & \\
\hline
\end{tabular}

Toelichting Door de aard van het materiaal is het niet mogelijk om Geleidingsvermogen $\mathrm{mS} / \mathrm{cm} 25^{\circ} \mathrm{C}$ uit te voeren.

De vermelde toetswaarden staan vermeld in de Uitvoeringsbesluit Meststoffenwet.

Contact \& info Monster genomen door.

Derden

Contactpersoon monstername: Bram Jansen: 0652002137

$\mathrm{Na}$ verzending van dit verslag wordt, indien de aard en de onderzoeksmethode van het monster dit toelaat, het monster nog twee weken bij Eurofins Agro voor u bewaard. Binnen deze tijd kunt u eventueel reclameren en/of aanvullend onderzoek aanvragen.

Pagina: 1

Totaal aantal pagina's: 2

$901608,15-10-2018$ 
monster 3a hellen

\begin{tabular}{|c|c|c|c|}
\hline Mothodo & 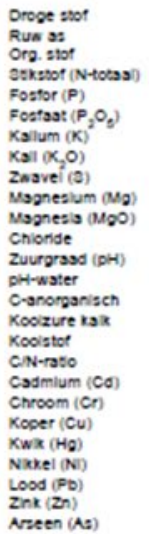 & $\begin{array}{l}0 \\
0 \\
0 \\
0 \\
0 \\
0 \\
0 \\
0\end{array}$ & 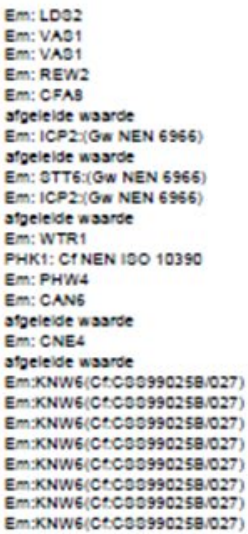 \\
\hline
\end{tabular}

Q Methooe geaccredteerd door RvA

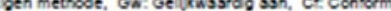

Bl deze vernchtng ia de gesiede houdossmedastermun tussen monatemame en anayse overschreden.

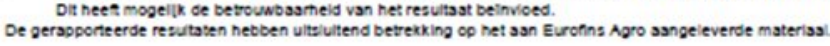

Pagina: 2

Totaal aantal pagina's: 2

$901608,15-10-2018$ 


\section{Bijlage 2 Bemestende waarde analyse dikke fractie digestaat}

\begin{tabular}{|c|c|c|c|c|}
\hline \multicolumn{5}{|c|}{$\because$ eurofins } \\
\hline & \multicolumn{3}{|c|}{$\begin{array}{l}\text { Mestonderzoek } \\
\text { Bemestende waarde } \\
\text { Monster 3B Hellen }\end{array}$} & $\begin{array}{l}\text { Eurofins Agro } \\
\text { Postbus } 1700 \\
\text { NL - } 6700 \text { AD Wageningen }\end{array}$ \\
\hline & \multicolumn{3}{|c|}{ Uw klantnummer: 8278474} & $\begin{array}{l}\text { E klantenservice.mest@eurofins-agro.com } \\
\text { I wmw.eurofins-agro.com }\end{array}$ \\
\hline & \multicolumn{3}{|c|}{$\begin{array}{l}\text { Acrres WUR PPO } \\
\text { D. Durksz } \\
\text { Edelhertwg } 1 \\
\text { 8219 PH LELYSTAD }\end{array}$} & \\
\hline Onderzoek & $\begin{array}{l}\text { Onderzoek-/ordernr: } \\
735051 / 004478153\end{array}$ & $\begin{array}{l}\text { Datum monstername: } \\
11-09-2018\end{array}$ & $\begin{array}{l}\text { Datum verslag: } \\
\text { 19-09-2018 }\end{array}$ & $\begin{array}{l}\text { Subsidieverlener. } \\
\text { Eurofins Agro, Kortingsregeling } \\
\text { Postbus } 170,6700 \text { AD WAGENINGEN }\end{array}$ \\
\hline \multirow{12}{*}{$\begin{array}{l}\text { Resultaat } \\
\text { weergegeven in } \\
\text { het product }\end{array}$} & & Eenheid & Resultaat & \\
\hline & Droge stof & $g \mathrm{DS} / \mathrm{kg}$ & 281 & \\
\hline & Ruw as & g RAS $/ \mathrm{kg}$ & 133 & \\
\hline & Organische stof & g OS/kg & 148 & \\
\hline & Stikstof & $g \mathrm{~N} / \mathrm{kg}$ & 6.20 & \\
\hline & $\mathrm{C} / \mathrm{N}$-ratio & & 11 & \\
\hline & Ammoniak-stikstof & $g \mathrm{NH}_{3}-\mathrm{N} / \mathrm{kg}$ & 1.1 & \\
\hline & Stikstof-organisch & $g \mathrm{~N}$-org/kg & 5.1 & \\
\hline & $\begin{array}{l}\text { Fosfor } \\
\text { Fosfaat }\end{array}$ & $\begin{array}{l}\mathrm{g} \mathrm{P} / \mathrm{kg} \\
\mathrm{g} \mathrm{P}_{2} \mathrm{O}_{g} / \mathrm{kg}\end{array}$ & $\begin{array}{l}2,15 \\
4.92 \\
\end{array}$ & \\
\hline & $\begin{array}{l}\text { Kalium } \\
\text { Kali }\end{array}$ & $\begin{array}{l}\mathrm{g} \mathrm{K} / \mathrm{kg} \\
\mathrm{g} \mathrm{K} \mathrm{K}_{2} \mathrm{O} / \mathrm{kg}\end{array}$ & $\begin{array}{l}4.8 \\
5.8 \\
\end{array}$ & \\
\hline & $\begin{array}{l}\text { Magnesium } \\
\text { Magnesia }\end{array}$ & $\begin{array}{l}g \mathrm{Mg} / \mathrm{kg} \\
\mathrm{g} \mathrm{MgO} / \mathrm{kg}\end{array}$ & $\begin{array}{l}1.9 \\
3.2\end{array}$ & \\
\hline & $\begin{array}{l}\text { Natrium } \\
\text { Natron }\end{array}$ & $\begin{array}{l}\stackrel{g \mathrm{Na} / \mathrm{kg}}{\mathrm{N} \mathrm{N}_{2} \mathrm{O} / \mathrm{kg}}\end{array}$ & $\begin{array}{l}0.8 \\
1,1\end{array}$ & \\
\hline
\end{tabular}

\footnotetext{
Toelichting De werkingsciffers voor deze mestsoort zijn op de achterzijde vermeld. Indien er geen mestsoort is opgegeven, zijn er standaard werkingscijfers afgedrukt.

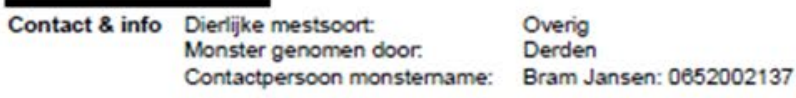

$\mathrm{Na}$ verzending van dit verslag wordt, indien de aard en de onderzoekmethode van het monster dit toelaat, het monster nog twee weken bij Eurofins Agro voor u bewaard. Binnen deze tjd kunt u eventueel reclameren en/of aanvullend onderzoek aanvragen.

\begin{tabular}{|c|c|c|c|c|c|c|}
\hline \multirow[t]{4}{*}{ Mothode } & 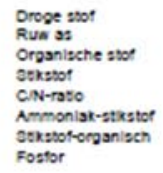 & Q & 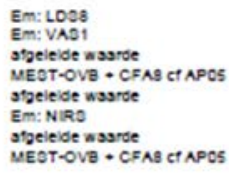 & $\begin{array}{l}\text { Foatag: } \\
\text { Kalum } \\
\text { Kall } \\
\text { Magneaium } \\
\text { Magnesia } \\
\text { Natrum } \\
\text { Naron }\end{array}$ & 0 & 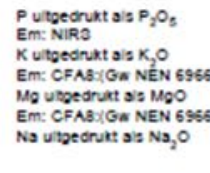 \\
\hline & \multicolumn{6}{|c|}{ 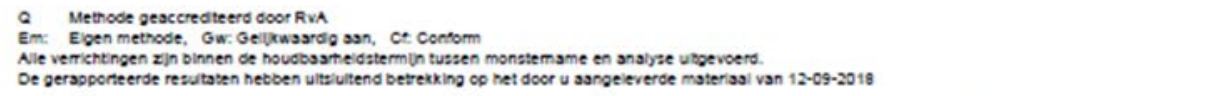 } \\
\hline & \multicolumn{3}{|c|}{$\begin{array}{l}\text { Pagina: } 1 \\
\text { Totaal aantal pagina's: } 2\end{array}$} & \multicolumn{3}{|c|}{ 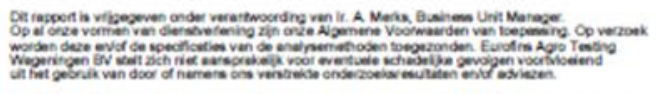 } \\
\hline & \multicolumn{3}{|c|}{$735051,19-09-2018$} & \multicolumn{3}{|c|}{ 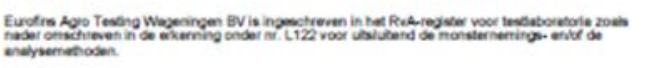 } \\
\hline
\end{tabular}


Monster 3B Hellen

\begin{tabular}{|c|c|c|c|c|c|c|c|}
\hline $\begin{array}{l}\text { Werkingscijfers } \\
\text { grasland }\end{array}$ & \multicolumn{3}{|c|}{ Stikstof } & \multicolumn{2}{|c|}{ Fosfaat } & \multicolumn{2}{|l|}{ Kali } \\
\hline \multirow{2}{*}{ bouwland } & $\begin{array}{l}\text { Bovengronds } \\
\text { werking minerale stikstof }(\%) \\
\text { werking organische stikstof }(\%)\end{array}$ & $\begin{array}{ll}22 \\
6\end{array}$ & $\begin{array}{l}6 \\
18\end{array}$ & 100 & 0 & 100 & 0 \\
\hline & $\begin{array}{l}\text { Bovengronds } \\
\text { werking minerale stikstof }(\%) \\
\text { werking organische stikstof }(\%)\end{array}$ & $\begin{array}{l}75 \\
30\end{array}$ & & 60 & 40 & 100 & \\
\hline \multirow{2}{*}{ Toelichting } & \multicolumn{7}{|c|}{$\begin{array}{l}\text { Voor het bepalen van de totale stikstofwerking moet de werking van het } \\
\text { minerale en organische deel worden opgeteld. }\end{array}$} \\
\hline & \multicolumn{7}{|c|}{$\begin{array}{l}\text { De totale werkzame hoeveelheid is als volgt te berekenen: } \\
\text { gehalte } \times \text { werking } \times \text { DM-gift }\end{array}$} \\
\hline
\end{tabular}

Pagina: 2

Totaal aantal pagina's: 2

735051, 19-09-2018 


\section{Bijlage 3 Compostanalyse vermicompost van digestaat}

\section{: eurofins}

$$
\text { Agro }
$$

Kwaliteitsonderzoek

Compost

Monster 4A

Uw klantnummer: 8278474

Eurofins Agro

PL - $6700 \mathrm{AD}$ Wageningen

T monstername: Mathieu Eugelink: 0652002180

T klantenservice: 0888761006

E klantenservice.mest@eurofins-agro.com

www.eurofins-agro.com

Acrres WUR PPO

D. Durksz

Edelhertwg 1

8219 PH LELYSTAD

\begin{tabular}{ll}
\hline Onderzoek & Analyse-/ordernummer. \\
& $2018901854 / 004522128$ \\
& Type monster. \\
& Compost (overig)
\end{tabular}

Datum verslag:

Subsidieverlener:

Eurofins Agro, Kortingsregeling

Postbus 170, 6700 AD WAGENINGEN

Monster 4A Hellen Elissen 3750368400

\begin{tabular}{|c|c|c|c|c|c|}
\hline Resultaat & & Eenheid & Resultaat & Toetswaarde & Resultaat in produkt $(\mathrm{g} / \mathrm{kg})$ \\
\hline \multirow{19}{*}{$\begin{array}{l}\text { bepaald in het } \\
\text { monster volgens } \\
\text { heopoder } \\
\text { heronder } \\
\text { vermelde nomen }\end{array}$} & Ruw as & $\mathrm{g} / \mathrm{kg} \mathrm{ds}$ & 473 & & \\
\hline & Stikstof $(\mathrm{N})$ & $\mathrm{g} / \mathrm{kg} d \mathrm{~s}$ & 20.5 & & 6.5 \\
\hline & Fosfor (P) & $g / \mathrm{kg} d s$ & 7 & & \\
\hline & Fosfaat $\left(\mathrm{P}_{2} \mathrm{O}_{5}\right)$ & $\mathrm{g} / \mathrm{kg} \mathrm{ds}$ & 16.0 & & 5.04 \\
\hline & Zwavel (S) & $g / k g d s$ & 4.8 & & 1.5 \\
\hline & Magnesium (Mg) & $g / \mathrm{kg} d s$ & 6.1 & & \\
\hline & Magnesia $(\mathrm{MgO})$ & $g / k g d s$ & 10 & & 3.2 \\
\hline & Chloride & $\mathrm{g} / \mathrm{kg} \mathrm{ds}$ & 3.7 & & \\
\hline & Zuurgraad (pH) & & 6.4 & & \\
\hline & pH-water & & 6.4 & & \\
\hline & $\mathrm{C} / \mathrm{N}$-ratio & & 14 & & \\
\hline & Cadmium (Cd) & $\mathrm{mg} / \mathrm{kg} \mathrm{ds}$ & 0.29 & 1.00 & \\
\hline & Chroom (Cr) & $\mathrm{mg} / \mathrm{kg}$ ds & 20 & 50 & \\
\hline & Koper (Cu) & $\mathrm{mg} / \mathrm{kg}$ ds & 23 & 90 & \\
\hline & Kwik ( $\mathrm{Hg})$ & $\mathrm{mg} / \mathrm{kg} \mathrm{ds}$ & 0.05 & 0.30 & \\
\hline & Nikkel (Ni) & $\mathrm{mg} / \mathrm{kg} \mathrm{ds}$ & 12 & 20 & \\
\hline & Lood $(\mathrm{Pb})$ & $\mathrm{mg} / \mathrm{kg} \mathrm{ds}$ & $<6,2$ & 100 & \\
\hline & Zink (Zn) & $\mathrm{mg} / \mathrm{kg}$ ds & 100 & 290 & \\
\hline & Arseen (As) & $\mathrm{mg} / \mathrm{kg} \mathrm{ds}$ & 1.6 & 15 & \\
\hline
\end{tabular}

\section{Toelichting De vermelde toetswaarden staan vermeld in de Uitvoeringsbesluit Meststoffenwet.}

\section{Contact \& info Monster genomen door: \\ Derden \\ Contactpersoon monstername: Bram Jansen: 0652002137}

$\mathrm{Na}$ verzending van dit verslag wordt, indien de aard en de onderzoeksmethode van het monster dit toelaat, het monster nog twee weken bij Eurofins Agro voor u bewaard. Binnen deze tijd kunt u eventueel reclameren en/of aanvullend onderzoek aanvragen. 


\section{Monster 4A}

\begin{tabular}{|c|c|c|c|}
\hline Mothodo & 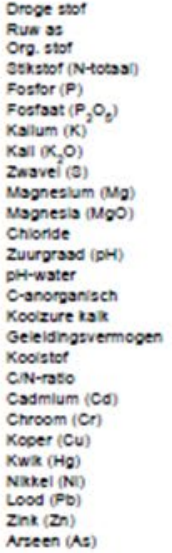 & $\begin{array}{l}0 \\
0 \\
0 \\
0 \\
0 \\
0 \\
0 \\
0\end{array}$ & 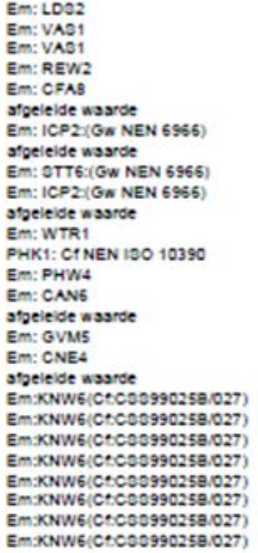 \\
\hline
\end{tabular}

Q. Methode geaccredteerd door RvA

Em: Eben methode, Gw: Gellkwasrdo san, Ce Contorm

Nie verrichtngen zin binnen de gesie ide housbasmedisterm un tussen monatemame en ana yse uspevoerd.

Pagina: 2

Totaal aantal pagina's: 2

$901854,19-11-2018$ 


\section{Bijlage 4 Bemestende waarde analyse vermicompost van digestaat}

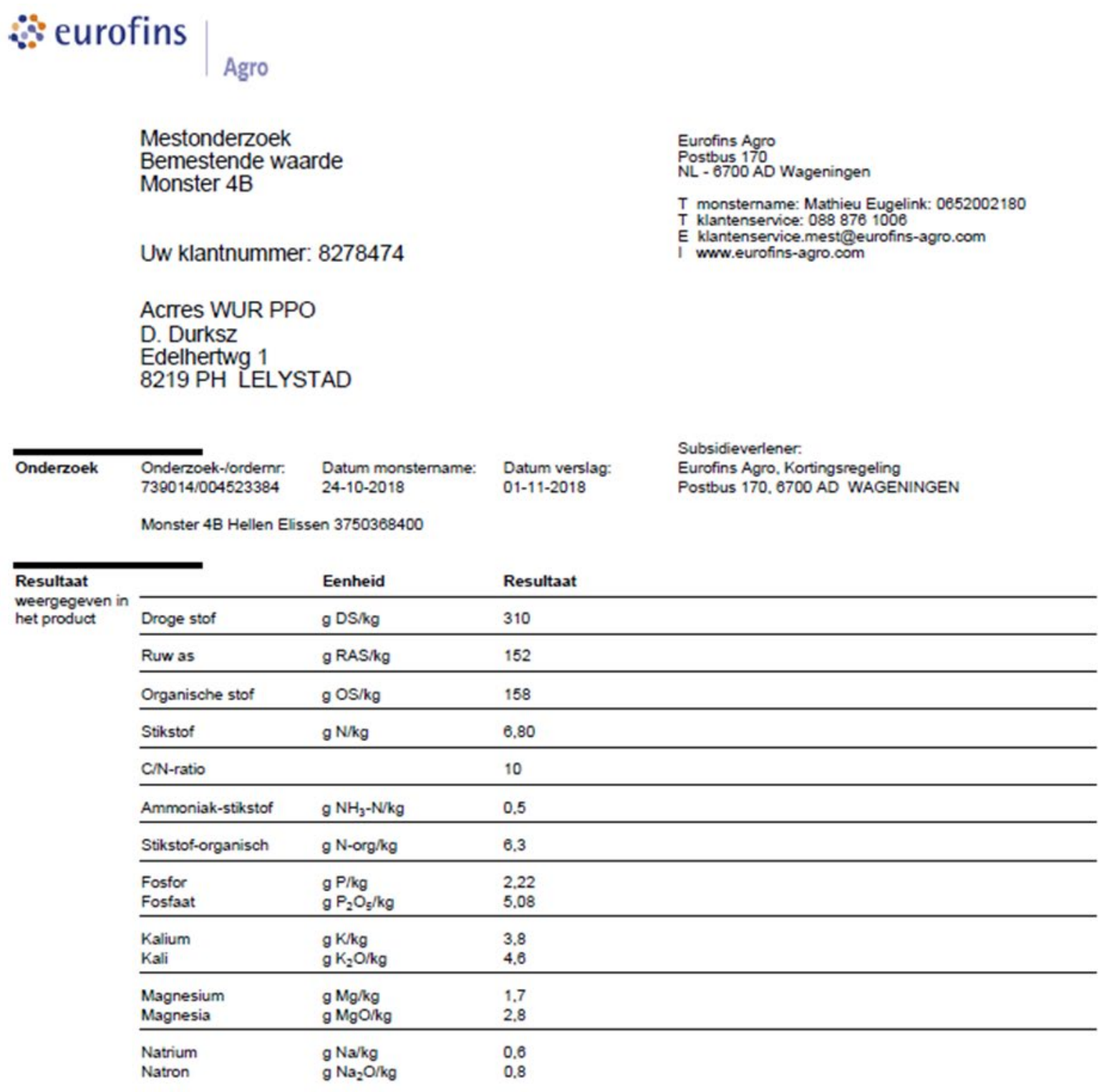

Toelichting Monster 4 B Hellen Elissen 3750368400

De werkingscifers voor deze mestsoort zijn op de achterzije vermeld. Indien er geen mestsoort is opgegeven, zijn er standaard werkingscijfers afgedrukt.

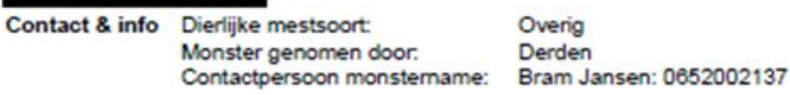

Na verzending van dit verslag wordt, indien de aard en de onderzoekmethode van het monster dit toelaat, het monster nog twee weken bij Eurofins Agro voor u bewaard. Binnen deze tjjd kunt u eventueel reclameren en/of aanvullend onderzoek aanvragen. 


\section{Monster 4B}

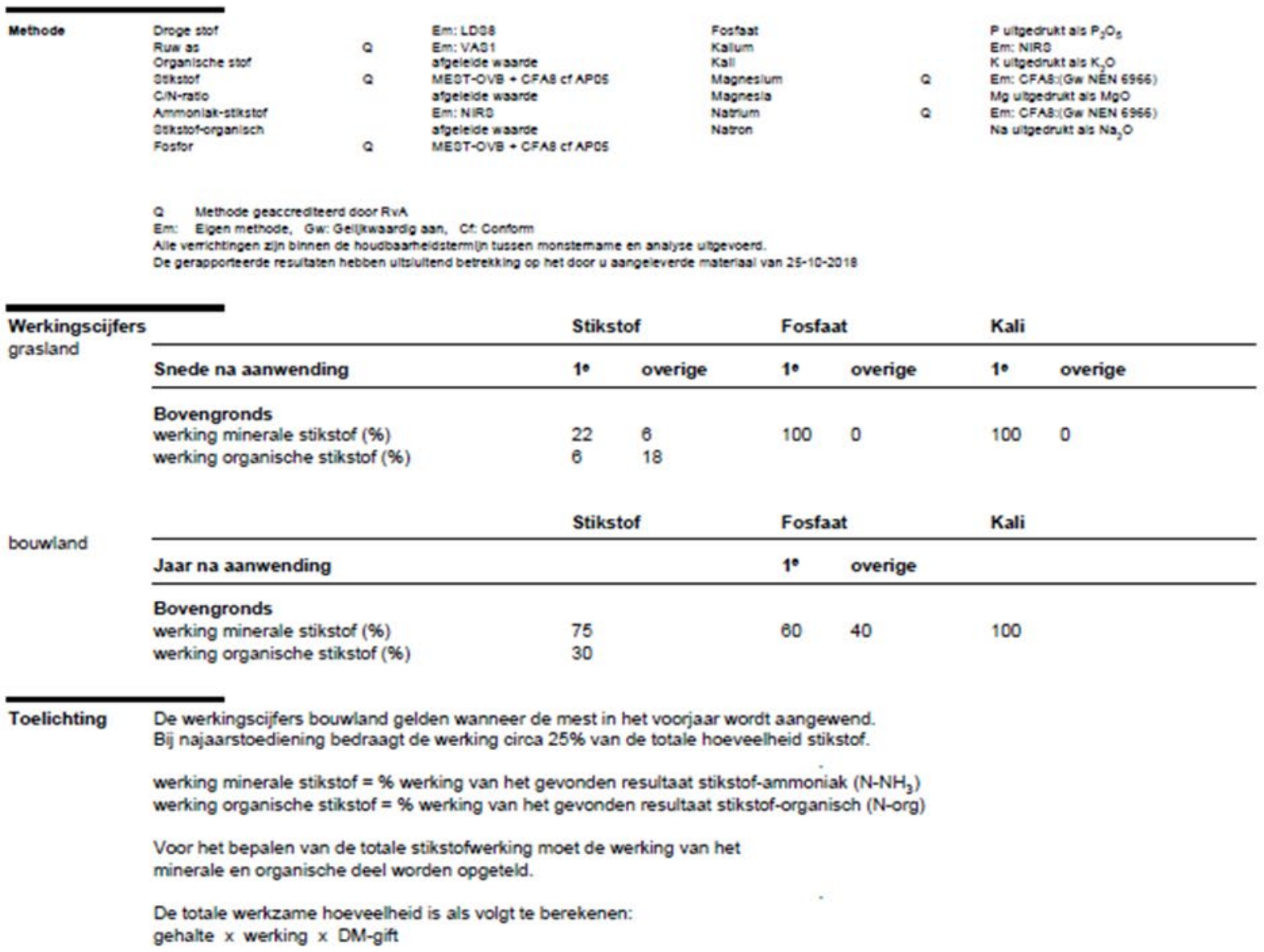

Pagina: 2

Totaal aantal pagina's: 2

739014, 01-11-2018 

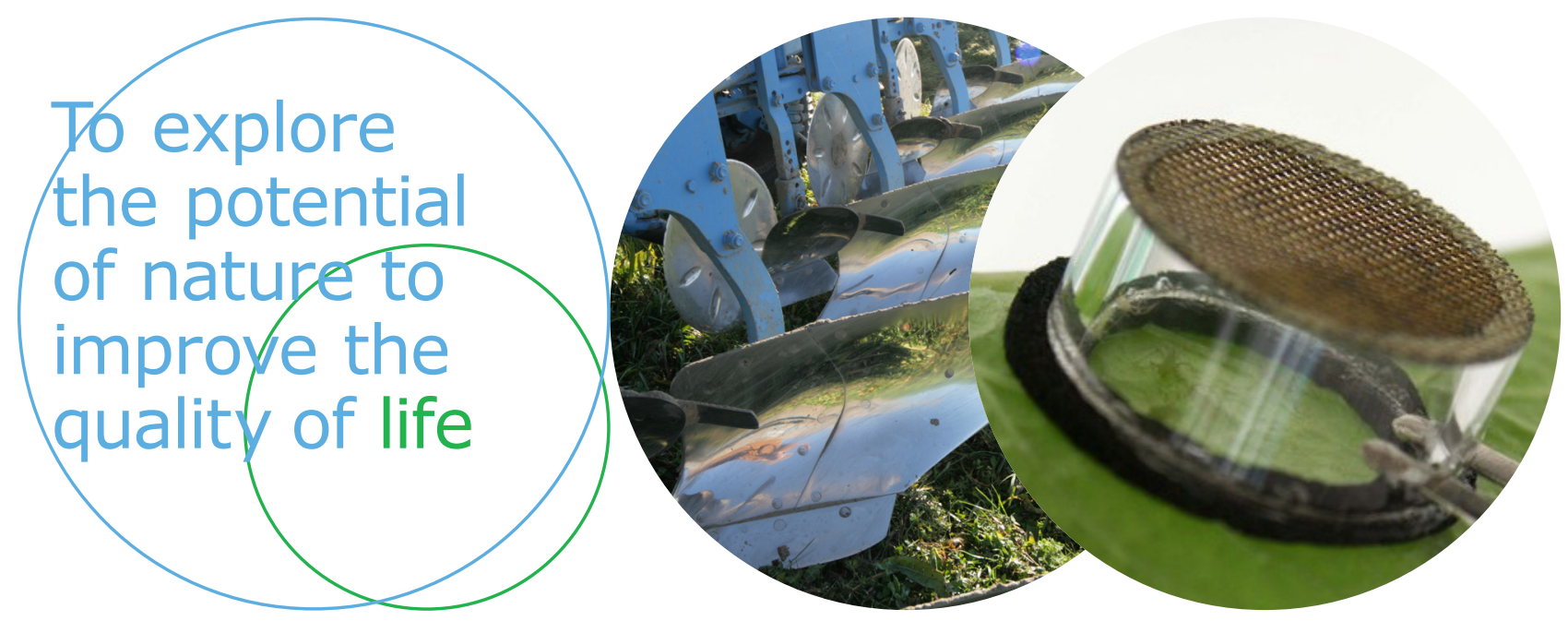

Correspondentie adres voor dit rapport: Wageningen University \& Research | Open Teelten

Edelhertweg 1

Postbus 430

8200 AK Lelystad

T (+31)320 291111

www.wur.nl/openteelten

Rapport WPR-815
De missie van Wageningen University \& Research is 'To explore the potential of nature to improve the quality of life'. Binnen Wageningen University \& Research bundelen 9 gespecialiseerde onderzoeksinstituten van stichting DLO en Wageningen University hun krachten om bij te dragen aan de oplossing van belangrijke vragen in het domein van gezonde voeding en leefomgeving. Met ongeveer 30 vestigingen, 6.000 medewerkers en 9.000 studenten behoort Wageningen University \& Research wereldwijd tot de aansprekende kennisinstellingen binnen haar domein.

De integrale benadering van de vraagstukken en de samenwerking tussen verschillende disciplines vormen het hart van de unieke Wageningen aanpak.

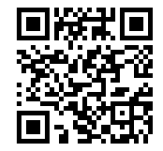

